\title{
$28 \mathrm{~S}$ ribosome degradation in lymphoid cell apoptosis: evidence for caspase and Bcl-2-dependent and -independent pathways
}

\author{
$\mathrm{KL} \mathrm{King}^{1,2}$, CM Jewell ${ }^{1}$, CD Bortner ${ }^{1}$ and JA Cidlowski ${ }^{*, 1}$ \\ ${ }^{1}$ Laboratory of Signal Transduction, National Institute of Environmental Health \\ Sciences, National Institute of Health, MD E2-02, Research Triangle Park, NC \\ 27709, USA \\ 2 Raymond Walters College, University of Cincinnati, Cincinnati, OH 45236, USA \\ * Corresponding author: JA Cidlowski, Laboratory of Signal Transduction, \\ National Institute of Environmental Health Sciences, National Institute of \\ Health, MD E2-02, PO Box 12223, Research Triangle Park, NC 27709, USA. \\ Tel: 919-541-1564; Fax: 919-541-1367; E-mail: cidlowski@niehs.nih.gov
}

Received 9.11.99; revised 16.5.00; accepted 14.6.00

Edited by ML Gougeon

\begin{abstract}
Apoptosis, a physiological form of cell death, is characterized by the activation of a program that kills cells and recycles their constituents. We have used thymoma cell lines to examine the role of $\mathrm{Bcl}-2$ and caspases in ribosomal destruction during apoptosis. Glucocorticoid- and calcium ionophore (A23187)induced apoptosis of S49 Neo cells resulted in both 28S rRNA and DNA degradation. Interestingly, anisomycin, a potent protein synthesis inhibitor, also induced 28S rRNA and DNA fragmentation suggesting that the responsible nucleases are present in the viable cells and become activated during apoptosis. The anti-apoptotic protein, Bcl-2, inhibited both glucocorticoid- and anisomycin-induced DNA and 28S rRNA degradation but could not protect against A23187-induced nucleic acid degradation. We next examined the role of caspase activation in the generation of 28S rRNA degradation through the use of ZVAD, a general caspase inhibitor. Under conditions where ZVAD substantially decreased 28S rRNA degradation induced by glucocorticoid or anisomycin, no decrease was observed when A23187 was used to induce apoptosis. Surprisingly, RNA degradation, like DNA degradation, occurs exclusively in shrunken lymphocytes but not those with normal cell volume despite equivalent exposure of the cells to the apoptotic signals. Together, these findings indicate the ribosome is a specific target for death effectors during apoptosis and that a caspase/Bcl-2-independent pathway exists to activate its destruction. Cell Death and Differentiation (2000) 7, 994-1001.
\end{abstract}

Keywords: apoptosis; glucocorticoids; RNA degradation; ribosomes

Abbreviations: ANIS, anisomycin; dex, dexamethasone

\section{Introduction}

Apoptosis participates in many physiological and pathological processes including embryonic development, tissue homeostasis, and shaping of the immune response. ${ }^{1,2}$ Morphological hallmarks of apoptosis include cell shrinkage, loss of cell-cell contact, and chromatin condensation. During the final stage of apoptosis, the cell breaks into small apoptotic bodies that are phagocytosed by macrophages or neighboring cells, so that, unlike necrosis, no inflammatory response is elicited. Biochemical changes are also distinct and dramatic during apoptosis where the cell systematically destroys vital cellular components through the activation of catabolic enzymes. Several proteases, known as caspases, are being investigated for their role in apoptosis. For example, the interleukin$1-\beta$ converting enzyme (ICE)-like family of cysteine proteases plays a pivotal role in cell death. ${ }^{3-7}$ Interestingly, recent evidence $^{8}$ indicates that both caspase-dependent and -independent cell death pathways exist in lymphocytes. Additionally, the activation of nucleases leading to the degradation of DNA and RNA has been proposed to be an irreversible commitment step in the induction of apoptosis. ${ }^{9}$ Indeed, a hallmark feature of apoptosis is internucleosomal DNA degradation that results in the formation of multiples of 180-200 base pair DNA fragments. Thus, the destruction of cellular components by catabolic enzymes plays a major role in apoptosis.

One extensively-studied model system for apoptosis is the glucocorticoid-induced death of immature thymocytes. In this system, treatment of adrenalectomized rats with the synthetic glucocorticoid dexamethasone (dex) causes rapid loss of thymocytes by apoptosis. Within 2 days following steroid treatment, thymic mass is reduced by $50 \%$ due solely to the loss of immature thymocytes. ${ }^{10}$ Primary cultures of thymocytes and most thymoma cell lines also are exquisitely sensitive to glucocorticoids, and the glucocorticoid receptor is required for cytotoxic effects to occur. However, the precise mechanism by which glucocorticoids induce apoptosis is unknown. Thymocytes undergoing glucocorticoid-induced cell death show classic features of apoptosis including general increases in protein, DNA and RNA degradation. ${ }^{11-14}$ Steroid-induced RNA degradation occurs rapidly after hormone administration. In dex-treated rat thymocytes, RNA degradation is detectable as early as $2.5 \mathrm{~h}$ after steroid treatment and by $4 \mathrm{~h}$ there is a $50 \%$ increase in RNA degradation. ${ }^{11}$ Additionally, the ability to synthesize new proteins has been shown to be inhibited during the cell death process. ${ }^{15,16}$

One of the RNA components of the large ribosomal subunit, 28S rRNA, has been shown to be degraded during apoptosis in a rat myeloid leukemia cell line, ${ }^{17,18}$ human lymphocytes, ${ }^{19}$ bovine endothelial cells, as well as primary 
cultures of prednisone treated rat thymocytes. ${ }^{18}$ Samali et $a{ }^{20}$ have shown that degradation of $28 \mathrm{~S}$ rRNA occurs in some but not all cell types and can occur independent of DNA fragmentation. Additionally, Houge et al, ${ }^{18}$ have mapped the cleavage sites on the 28S rRNA molecule in apoptotic IPC-81 cells induced by CAMP to the D2 and D8 regions of the molecule. However, the mechanisms of regulation for RNA degradation are not well understood. We have now used the thymoma cell line, S49, as a model system to further examine the destruction of ribosomal components during apoptosis and the signaling pathways associated with this rRNA degradation. We show that $28 \mathrm{~S}$ rRNA fragmentation consistently occurs in S49 cells irrespective of the death signal used to initiate apoptosis and in the absence of protein synthesis. Additionally, we show a direct correlation between cell shrinkage and $28 \mathrm{~S}$ rRNA degradation. Furthermore, Bcl-2 overexpression and inhibition of caspase activity only partially abrogates $28 \mathrm{~S}$ ribosomal RNA degradation.

\section{Results \\ DNA and RNA degradation occurs in response to multiple apoptotic agents}

The activation of nucleases appears to be a final commitment step in the apoptotic process, and thus, we wanted to examine the effect of nuclease activation on RNA and DNA integrity. Previous studies have shown that the synthetic glucocorticoid, dexamethasone (dex), induces apoptosis in S49 Neo cells. $^{15,21,22}$ S49 Neo cells were treated with $0.25 \mu \mathrm{M}$ dex for $24 \mathrm{~h}$ and the number of apoptotic cells, determined by microscopic analysis and trypan blue exclusion, increased from $2.7 \pm 0.9 \%$ to $30.4 \pm 4.9 \%$. Nucleases that cleave DNA internucleosomally were also activated demonstrating that the cells were dying by apoptosis (Figure 1A). To determine if apoptotic nucleases degraded RNA as well, total RNA was isolated and separated by non-denaturing agarose gel electrophoresis. The band of intact $28 \mathrm{~S}$ rRNA was diminished and one prominent, novel band was visible, indicating that $28 \mathrm{~S}$ rRNA was being cleaved to produce a smaller fragment (Figure 1A). This degradation appeared to occur concomitantly with the apoptotic morphology as judged microscopically and the associated DNA fragmentation. 18S rRNA did not appear to be grossly degraded in either control or glucocorticoid treated cells.

It is conceivable that RNA degradation is part of the steroid signal transduction pathway because these hormones are well known to inhibit protein synthesis in lymphocytes ${ }^{15,16}$ or, alternatively, RNA degradation may occur independent of the death signal employed. To distinguish between these two possibilities, S49 Neo cells were induced to undergo apoptosis via different stimuli that utilized alternative signal transduction pathways. Treatment of S49 Neo cells with the protein synthesis inhibitor, anisomycin, (1.5 $\mu \mathrm{M}, \mathrm{ANIS})$ or with the calcium ionophore, A23187 $(2 \mu \mathrm{M})$ resulted in apoptosis as demonstrated by the presence of internucleosomal DNA cleavage (Figure $1 A)$. Because these agents induced death with different kinetics than dex, DNA and total RNA were isolated from treated cells when approximately $30 \%$ of the cells were apoptotic as determined by microscopic analysis and trypan blue dye exclusion to ensure that A23187-, anisomycin-, and dex-treated cells were at similar stages of apoptosis. As with glucocorticoid treatment, anisomycin increased the number of apoptotic cells from $2.0 \pm 0.6 \%$ to $31 \pm 1.1 \%$, and A23187-treatment increased the number of apoptotic cells from $2.7 \pm 0.3 \%$ to $33.1 \pm 6.8 \%$. Both agents induced internucleosomal cleavage of DNA and $28 \mathrm{~S}$ rRNA degradation resulting in the formation of the novel RNA degradation product (Figure 1A). These data suggest that $28 \mathrm{~S}$ rRNA degradation is not the result of a specific death stimulus but appears to be part of a common apoptotic pathway downstream from signal-specific events. Furthermore, these findings suggest that nucleases responsible for RNA degradation are already present in the cells since these experiments, specifically those using anisomycin, were conducted under conditions where protein synthesis is effectively inhibited.

\section{Degradation of $28 S$ rRNA is partially inhibited by $\mathrm{Bcl}-2$}

$\mathrm{Bcl}-2$ expression has been shown to protect $\mathrm{S} 49$ cells from dex-induced internucleosomal DNA degradation and apoptosis. ${ }^{15,23}$ To determine if $\mathrm{Bcl}-2$ had a similar protective effect against RNA degradation, S49 Bcl-2 cells were treated with dex, anisomycin and A23187 and RNA integrity was examined. The level of $\mathrm{Bcl}-2$ in these cells has been shown to be approximately 20 -fold greater than background (Huang and Cidlowski, unpublished observation). Consistent with previous studies, the number of apoptotic cells in dex-treated, Bcl-2 expressing cultures did not increase above $5 \%$ and no internucleosomal DNA fragmentation was observed, indicating that these cells were resistant to steroid-induced cell death (Figure 1B). ${ }^{15,23}$ In addition, RNA integrity was examined by agarose gel electrophoresis and the intact 28S rRNA band was not diminished and no novel bands were visible indicating that $\mathrm{Bcl}-2$ expression repressed dex-induced RNA degradation as well (Figure 1B). Thus, dex-induced $28 \mathrm{~S}$ rRNA degradation appears to be an apoptotic-specific event inhibited by $\mathrm{Bcl}-2$ expression. We also examined the ability of the protein synthesis inhibitor, anisomycin, to induce DNA fragmentation and 28S rRNA degradation in the Bcl-2 cells. As with dex treatment, the number of apoptotic cells in the $\mathrm{Bcl}-2$ expressing cultures did not increase above 5\% and neither DNA nor 28S rRNA degradation was visible indicating that $\mathrm{Bcl}-2$ can also protect against anisomycin induced apoptosis (Figure 1B). To determine if S49 Bcl-2 cells are capable of degrading 28S rRNA when undergoing apoptosis, cells were treated with $2 \mu \mathrm{M}$ A23187. Previous studies have shown that $\mathrm{Bcl}-2$ expression does not completely block A23187-induced apoptosis in S49 cells but confers only partial resistance. ${ }^{15}$ A23187-treatment increased the number of apoptotic cells from $1.7 \pm 0.6 \%$ to $30.0+1.3 \%$ and induced internucleosomal DNA fragmentation (Figure 1B). Additionally, the $28 \mathrm{~S}$ rRNA band was degraded in a manner very similar to that observed in apoptotic S49 cells (Figure 1B). Thus, apoptosis and $28 \mathrm{~S}$ 
S49 Neo

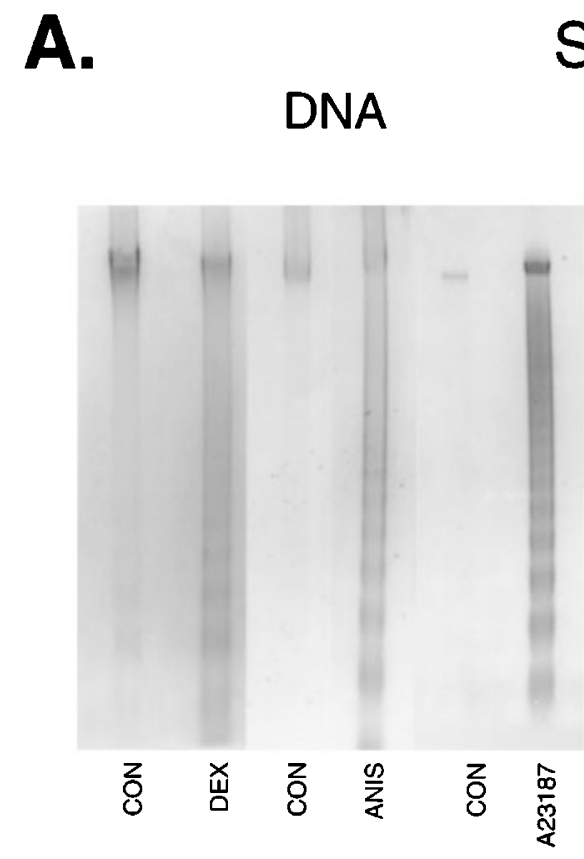

DNA

B.

\section{DNA}

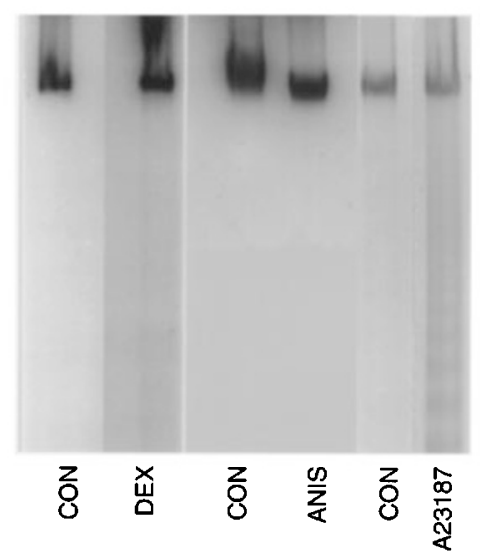

S49 Bcl-2

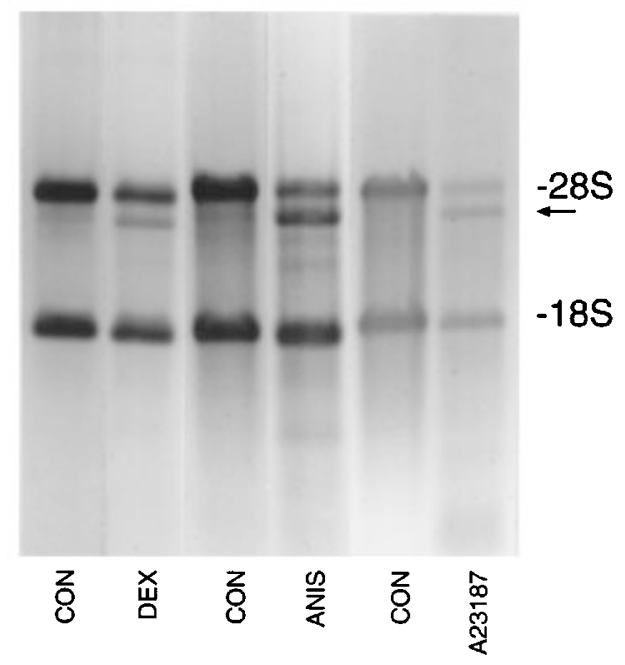

RNA

$-28 S$

$-18 S$

Figure 1 The effects of different apoptotic stimuli on DNA and RNA degradation in S49 Neo and S49 Bcl-2 cells. (A) S49 Neo cells were treated with vehicle (CON) or one of the following death signals: dexamethasone (DEX) $0.25 \mu \mathrm{M}$ for $24 \mathrm{~h}$; anisomycin (ANIS) $1.5 \mu \mathrm{M}$ for $12 \mathrm{~h}$; A23187 $2 \mu \mathrm{M}$ for $20 \mathrm{~h}$. DNA and RNA was isolated and subjected to agarose gel electrophoresis and ethidium bromide staining. 28S and 18S rRNA are marked. Note the appearance of a novel RNA band in death signal-treated S49 Neo RNA lanes (arrow). (B) S49 Bcl-2 cells were treated as described above and DNA and RNA were isolated and viewed in an ethidium bromide-stained agarose gel. Note no novel RNA band is visible in the dex- and anisomycin-treated S49 Bcl-2 RNA lane but is present in the A23187 treated lanes. Lanes shown are representative of three separate experiments

rRNA degradation appear to be tightly coupled. Interestingly, Bcl-2 cells are resistant to dex-induced but not ionophore-induced RNA degradation indicating that the RNA degradation pathway remains intact in the $\mathrm{Bcl}-2$ over-expressing cells. Additionally, this suggests that multiple signaling mechanisms can be employed to activate the catabolic component of the apoptotic machinery.

\section{Selective degradation of $28 \mathrm{~S}$ rRNA is partially inhibited by $\mathrm{Bcl}-2$}

Houge et al, ${ }^{17,18}$ used Northern blot analysis to map the apoptotic cleavage sites on the 28S rRNA molecule from IPC81 cells and bovine endothelial cells as well as primary thymocytes. In order to confirm $28 \mathrm{~S}$ rRNA degradation and 
compare the patterns of 28S rRNA fragmentation in dextreated $S 49$ cells to the results obtained by Houge et al, Northern blots of RNA from dex-treated S49-Neo cells were hybridized with probes that recognized the $5^{\prime}$ end of the $28 \mathrm{~S}$ rRNA. Representative hybridizations are shown in Figure 2. The $5^{\prime}$ probe recognized five prominent fragments approximately 2900, 2500, 550, 200 and 50 bases in size (Figure 2A). These data indicate that ribosomal RNA destruction occurs via a specific, non-random process during the catabolic phase of apoptosis. Anisomycin produced a similar pattern of $28 \mathrm{~S}$ rRNA degradation in S49 Neo cells. Near total 28S rRNA degradation was observed in A23187-treated S49 Neo cells, however, common degradation products were observed (see arrows). Overall, the pattern of degradation induced via different death stimuli using distinct signal transduction pathways appeared similar suggesting the involvement of a common ribonuclease.

To examine the effects of $\mathrm{Bcl}-2$ expression on $28 \mathrm{~S}$ rRNA cleavage, $\mathrm{S} 49 \mathrm{Bcl}-2$ cells were treated with dex, anisomycin, and A23187 and examined for 28S rRNA fragmentation by Northern blot analysis. Analysis of $28 \mathrm{~S}$ rRNA from dex- and anisomycin-treated $\mathrm{S} 49 \mathrm{Bcl}-2$ cells resulted in little $28 \mathrm{~S}$ rRNA fragmentation (Figure 2B). However, treatment of S49 $\mathrm{Bcl}-2$ cells with $\mathrm{A} 23187$ resulted in cleavage of the $28 \mathrm{~S}$ rRNA identical to the pattern observed in the absence of Bcl2 , suggesting the activation of a similar ribonuclease in a Bcl-2-independent apoptotic pathway. Interestingly, the extent of $28 \mathrm{~S}$ rRNA degradation in S49 $\mathrm{Bcl}-2$ cells was reduced over that observed in the absence of $\mathrm{Bcl}-2$, suggesting that $\mathrm{Bcl}-2$ overexpression can in part repress, but not inhibit, this catabolic pathway.
A.

\section{S49 Neo}

5'28S Probe

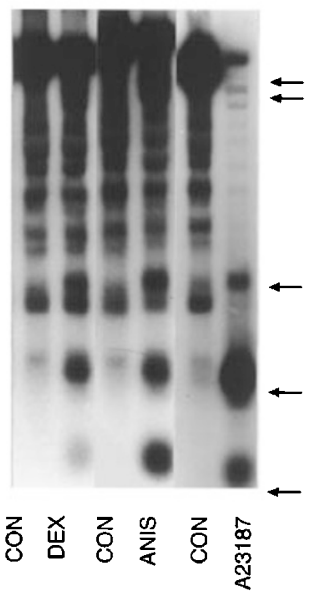

B.

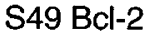

5' 28S Probe

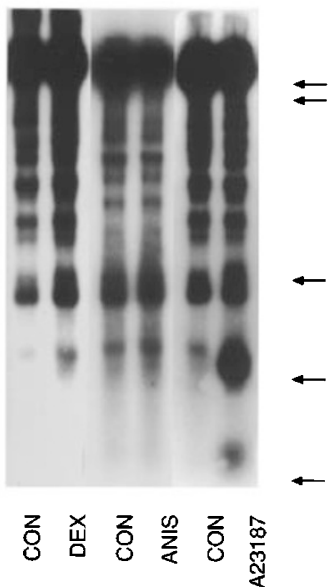

Figure 2 The effect of apoptotic stimuli on 28S rRNA integrity in S49 Neo and $\mathrm{S} 49 \mathrm{Bcl}-2$ cells. Autoradiographs of Northern blots of total RNA isolated from vehicle (CON), dexamethasone (DEX), anisomycin (ANIS), and A23187treated S49 Neo and S49 Bcl-2 cells. Arrows mark the positions of the major fragments of $28 \mathrm{~S}$ rRNA. Note the reduction in 28S rRNA degradation in the S49 Bcl-2 samples compared to S49 Neo cells. Samples shown are representative of three separate experiments

\section{Caspase dependent/independent 28S rRNA catabolism}

Caspases play a pivotal role in executing the apoptotic pathway, ${ }^{3,7}$ but alternative caspase independent pathways have recently been described. ${ }^{8}$ To determine if $28 \mathrm{~S}$ rRNA degradation is dependent on caspase activation, S49 Neo cells were treated with dex or anisomycin in the presence or the absence of the general caspase inhibitor ZVAD for $24 \mathrm{~h}$. Treatment with $75 \mu \mathrm{M}$ ZVAD decreased the percentage of apoptotic cells from $40.0 \pm 8.7 \%$ to $23.0 \pm 6.9 \%$ for dex and decreased the percentage apoptotic cells from $78.6 \pm 6.0 \%$ to $22.6 \pm 6.9 \%$ for anisomycin. DNA and RNA were isolated from each treatment and analyzed by gel electrophoresis. Both DNA and 28S rRNA degradation were reduced, but not fully eliminated in the dex plus ZVAD and the anisomycin plus ZVAD treated cells (Figure 3). Consistent with these results, analysis of RNA fragmentation by Northern blot also showed a decrease in the quantity of RNA fragments produced, although the patterns of degradation were remarkably similar. S49 Neo cells treated with specific caspase inhibitors such as DEVD (caspase-3), IETD (caspase-8), and LEHD (caspase-9) in the presence of dex resulted in a small protective effect, however not to the level observed in the presence of the pan-caspase inhibitor ZVAD (data not shown).

To determine if ZVAD had similar affects on A23187 induced apoptosis in S49 Neo and S49 Bcl-2 cells, these cells were treated with $2 \mu \mathrm{M}$ A23187 alone or in the presence of $75 \mu \mathrm{M}$ ZVAD. The addition of ZVAD did not substantially block the apoptotic effect of A23187 in either

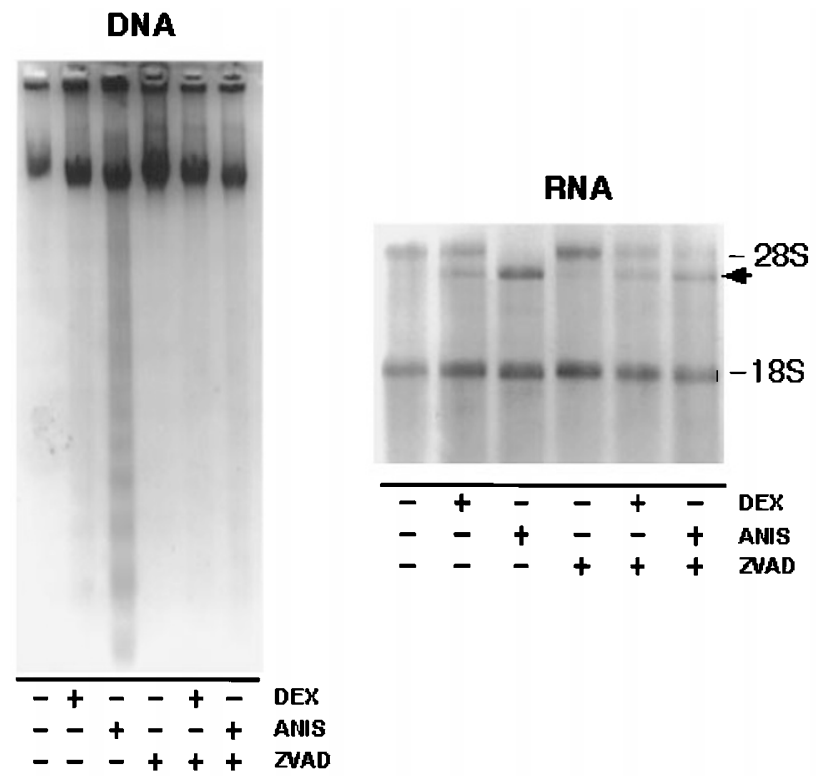

Figure 3 The effect of ZVAD on DNA and 28S rRNA degradation in S49 Neo cells. S49 Neo cells were treated with either dexamethasone (DEX) or anisomycin (ANIS) alone or in conjunction with ZVAD for $24 \mathrm{~h}$. DNA and RNA were isolated from each sample. $28 \mathrm{~S}$ and $18 \mathrm{~S}$ rRNA bands are indicated, and the degradation product is marked by an arrow. Note the reappearance of the intact $28 \mathrm{~S}$ rRNA band in the ANIS+ZVAD lane. The samples shown are representative of at least three separate experiments 
S49 Neo or S49 Bcl-2 cells. Although cell viability was not improved by the addition of the caspase inhibitor, a reduction of both DNA and 28S rRNA degradation was observed in S49 Neo cells upon addition of ZVAD (Figure 4). Interestingly, the combined protective effects of $\mathrm{Bcl}-2$ and ZVAD were not able to rescue cells from the calcium ionophore A23187-induced cell death (Figure 4) suggesting a caspase/Bcl-2-independent pathway for the catabolic effects during apoptosis. Additionally, S49 Neo and S49 $\mathrm{Bcl}-2$ cells treated with specific caspase inhibitors in the presence of A23187 also failed to protect these cells from apoptosis (data not shown).

Most apoptotic agents induce cell death in both a timeand concentration-dependent manner. Therefore, the inability of ZVAD to rescue both S49 Neo and S49 Bcl-2 cells from A23187-induced cell death lead us to examine the protective effect of ZVAD versus alterations in the concentration of the apoptotic agent A23187. S49 Neo and S49 Bcl-2 were treated with $0.1,0.5,1$, and $2 \mu \mathrm{M}$ of A23187 for $24 \mathrm{~h}$ in the presence and absence of $75 \mu \mathrm{M}$ ZVAD. Once again, the presence of ZVAD reduced, however did not completely inhibit 28S rRNA fragmentation, even at the lower concentrations of A23187 in S49 Neo cells (Figure 5). These data are similar to the results observed for $2 \mu \mathrm{M} \mathrm{A23187}$ as shown in Figure 4. Both 1 and $2 \mu \mathrm{M}$ A23187-induced 28S rRNA degradation in S49 $\mathrm{Bcl}-2$ expressing cells, which again was not inhibited by ZVAD. Interestingly, lower concentrations of A23187 failed to induce $28 \mathrm{~S}$ rRNA degradation in the Bcl-2 expressing cells, implying that this anti-apoptotic protein is functioning at some level to inhibit ionophore induced apoptosis.

\section{DNA}

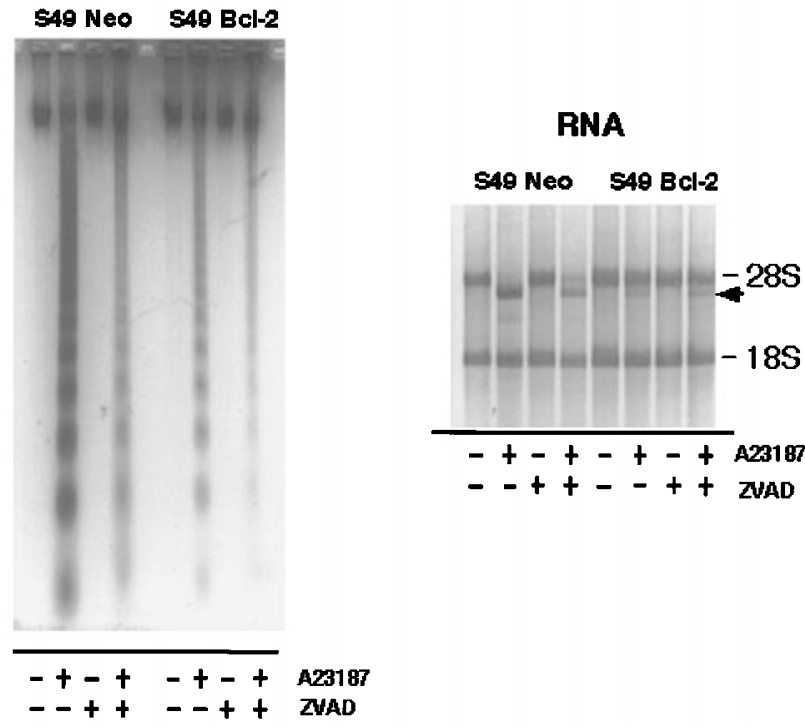

Figure 4 The effect of ZVAD on A23187 induced DNA and RNA degradation in $\mathrm{S} 49 \mathrm{Neo}$ and $\mathrm{S} 49 \mathrm{Bcl}-2$ cells. S49 Neo and S49 Bcl-2 cells were treated with either A23187 alone or in conjunction with ZVAD for $24 \mathrm{~h}$. DNA and RNA were isolated from each sample. The $28 \mathrm{~S}$ and $18 \mathrm{~S}$ rRNA bands are marked, and the degradation product is indicated by an arrow. Note the reappearance of the intact 28S rRNA band in the A23187+ZVAD lane for S49 Neo cells. The samples shown are representative of three experiments

\section{RNA catabolism occurs only in shrunken cells}

To date, all cells examined, including those used in these studies, shrink when undergoing apoptosis (for example, see $^{24}$ ), and only shrunken cells exhibit DNA degradation and effector caspase activation. ${ }^{25}$ To assess if cell shrinkage is coupled to $28 \mathrm{~S}$ rRNA degradation, S49 Neo cells were induced to undergo dex-induced apoptosis, then shrunken and non-shrunken cells were sorted by flow cytometry (Figure $6 \mathrm{~A})$. RNA was then isolated from each population and analyzed by agarose gel electrophoresis. Degraded $28 \mathrm{~S}$ rRNA was visible only in the pre-sorted and shrunken populations, but not the normal, non-shrunken cell population (Figure 6B). This suggests that only the shrunken population of cells degrade their RNA even though all of the cells were exposed to this apoptotic stimuli for an equivalent duration.

\section{Discussion}

The present study has demonstrated that ribonucleic acids are degraded under a variety of apoptotic conditions during thymocyte cell death. Additionally, specific fragmentation of $28 \mathrm{~S}$ rRNA occurs only in the shrunken apoptotic population of cells. Different apoptotic death signals in lymphocytes induced similar patterns of 28S rRNA degradation; however, A23187-treatment led to greater degradation of intact $28 \mathrm{~S}$ rRNA and the accumulation of smaller 28S rRNA fragments suggesting that degradation products are subsequently broken down into smaller pieces. The fact that 28S rRNA degradation could also be induced by a protein synthesis inhibitor suggests that, like other apoptotic effector molecules, enzymes responsible for 28S rRNA degradation are already present in cells and become active when apoptosis is induced. Bcl-2 expression provided resistance to $28 \mathrm{~S}$ rRNA degradation during glucocorticoid- and anisomycin-induced cell death but only partially affected death induced by the calcium ionophore A23187. 28S rRNA degradation induced by dex or anisomycin was reduced by caspase inhibition suggesting that caspases play an important role in RNA cleavage under these apoptotic conditions. However,

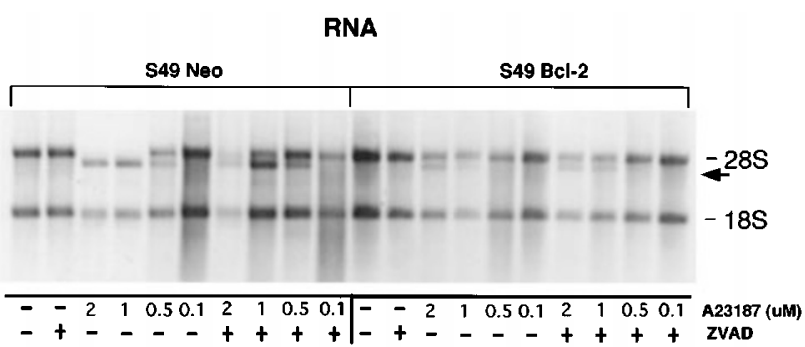

Figure 5 The effect of ZVAD on RNA degradation in S49 Neo and S49 Bcl-2 cells using various concentrations of A23187. S49 Neo and S49 Bcl-2 cells were treated with $0.1,0.5,1$, or $2 \mu \mathrm{M} \mathrm{A} 23187$ alone or in conjunction with ZVAD for $24 \mathrm{~h}$. RNA were isolated from each sample and the $28 \mathrm{~S}$ and $18 \mathrm{~S}$ rRNA bands are marked, and the degradation product is indicated by an arrow. Note the reappearance of the intact 28S rRNA band in the ZVAD lanes for S49 Neo cells treated with various concentrations of A23187 and the inability of these concentrations of A23187 to induce significant cleavage of the $28 \mathrm{~S}$ rRNA band in $S 49 \mathrm{Bcl}-2$ cells. The samples shown are representative of two experiments 
A.

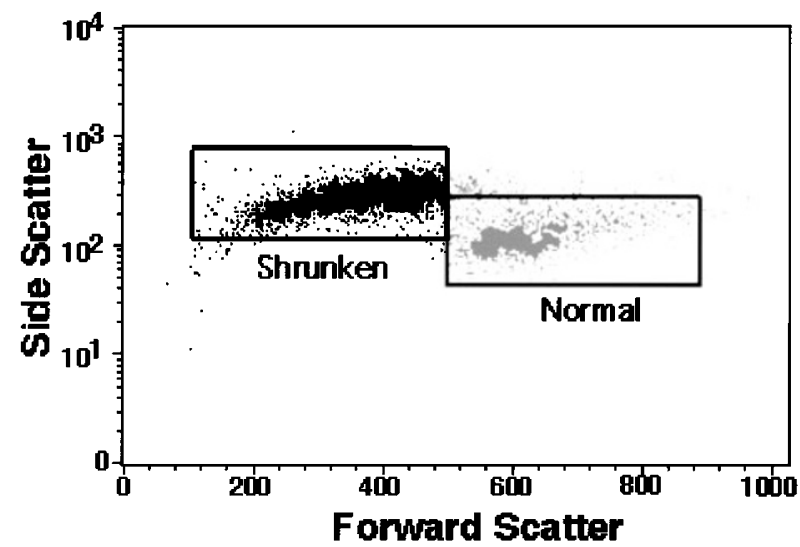

B. S49 Neo RNA

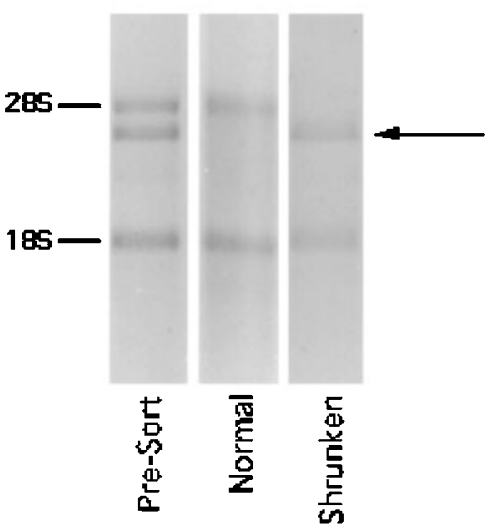

Figure 6 Only shrunken S49 Neo cells contain 28S rRNA degradation product. (A) S49 Neo cells were treated with dexamethasone for $42 \mathrm{~h}$. Cells were then collected for RNA (pre-sort) or sorted into normal cell size population or shrunken cell size population prior to RNA isolation. (B) RNA analysis of the pre-sort, normal and shrunken dex-treated S49 Neo cells. An arrow indicates the novel band. Note the novel $28 \mathrm{~S}$ rRNA band is the only $28 \mathrm{~S}$ band present in the shrunken cells. The DNA histogram and RNA lanes shown are representative of several experiments

caspase inhibition had little effect on either DNA or 28S rRNA degradation induced by $\mathrm{A} 23187$, even at various concentrations of this stimulus. These observations strongly suggest that a caspase/Bcl-2-independent pathway exists for the activation of cell death catabolism.

Regardless of the death stimulus employed, the pattern of $28 \mathrm{~S}$ rRNA fragmentation was remarkably similar. In most cases, the $5^{\prime}$ probe recognized five degradation products, indicating that specific sites on the RNA molecule were being cleaved. Houge et $a{ }^{18}{ }^{18}$ have used Northern blot analysis, primer extension, and $S 1$ nuclease protection to map cleavage sites in the 28S rRNA molecule in apoptotic IPC-81 cells with similarities apparent between our results and those reported previously. We both detected a 550 base and a 2900 base fragment recognized by a probe complimentary to the $5^{\prime}$ end of the 28S rRNA. However, unlike our results, Houge et $a l^{18}$ did not detect 2500, 200 and 50 base bands with their $5^{\prime}$ probe. These differences probably reflect the different probes used, differences in the percentage of apoptotic cells at the time of RNA isolation, and different death stimuli employed, all of which we have shown affect the extent of fragmentation and size of fragments produced.

Because 28S rRNA is a component of the ribosome, it is possible that degradation of this molecule inhibits protein synthesis. Indeed, it is widely recognized that glucocorticoid treatment of thymocytes results in a decrease in protein synthesis in addition to triggering death. ${ }^{15,16}$ This biochemical parameter can be separated from the apoptotic process by expression of $\mathrm{Bcl}-2$ in that dex-treated $\mathrm{S} 49 \mathrm{Bcl}-2$ cells, which show a decrease in protein synthesis, show no cell death. ${ }^{15}$ We have demonstrated that dex-treatment of S49 $\mathrm{Bcl}-2$ cells does not result in significant degradation of $28 \mathrm{~S}$ rRNA after $24 \mathrm{~h}$. If $28 \mathrm{~S}$ rRNA degradation is solely responsible for the glucocorticoid-induced inhibition of protein synthesis then $28 \mathrm{~S}$ rRNA degradation should also occur in dex-treated S49 Bcl-2 cells. These results strongly suggest that $28 \mathrm{~S}$ rRNA degradation is not responsible for steroid-induced protein synthesis inhibition, and RNase activity is tightly coupled to glucocorticoid-induced apoptosis but not to other glucocorticoid-mediated effects. In contrast to the S49 Bcl-2 cell response to dex-treatment, A23187 does induce apoptosis and 28S rRNA degradation suggesting that more than one pathway can activate $28 \mathrm{~S}$ rRNA degradation.

Cell shrinkage and activation of caspases are two distinct features of apoptotic cells suggesting a fundamental role for these two processes during apoptosis. In this study, we show that only shrunken cells exhibit 285 rRNA degradation. Additionally, ionic fluxes that induce cell shrinkage during apoptosis have been shown to be required to activate the nuclease responsible for this degradation. ${ }^{25,26}$ Inhibition of caspase activity reduced DNA and 28S rRNA degradation during glucocorticoidand anisomycin-induced apoptosis in S49 Neo cells suggesting that RNA degradation is a caspase-dependent process. However, the addition of ZVAD to either S49 Neo or $\$ 49 \mathrm{Bcl}-2$ cells treated with A23187 only minimally alters the extent of DNA or $28 \mathrm{~S}$ rRNA degradation. These data indicate that a caspase/Bcl-2-independent pathway exists for the activation of apoptosis.

The nucleases responsible for cleavage of both DNA and RNA have yet to be completely identified. However several potential candidates have been proposed as the apoptotic nuclease responsible for internucleosomal DNA cleavage including DNase I, Dnase II and NUC18. Recently, a caspase-dependent nuclease was isolated from mouse $T$ cell lymphoma cells designated CAD. ${ }^{27,28}$ Cytosolic extracts from normal, healthy cells were shown to contain nuclease activity upon treatment with caspase 3 , suggesting that activation of the apoptotic nuclease is a caspase-dependent process. This occurs by the ability of caspase 3 to inactivate an inhibitor protein, ICAD permitting the translocation of CAD to the nucleus. In our study, the pan caspase inhibitor 
ZVAD was shown to substantially decrease both DNA and rRNA degradation in dex and anisomycin treated S49 Neo cells. However, DNA and rRNA degradation in cells treated with the calcium ionophore A23187 were only partially inhibited in the presence of ZVAD. These observations suggest that other nucleases may be involved in the apoptotic process perhaps dependent on the specific stimulus applied to induce death.

Activation of catabolic enzymes appears to be inherently important in the apoptotic process. 28S rRNA degradation has been found in CAMP-induced apoptosis of a rat myeloid leukemia cell line, ${ }^{17,18} \gamma$-ray-induced apoptosis of human lymphocytes, ${ }^{19}$ in apoptotic bovine endothelial cells, and in primary cultures of prednisone-treated rat thymocytes, ${ }^{18}$ as well as systems described in this current study. In other systems, rRNA degradation is not associated with apoptosis suggesting that 28S rRNA cleavage is a cell type-dependent process. Several theories have been proposed for the role of RNA degradation in cell death. First, RNA turnover may be used to destroy RNA encoding proteins that antagonize the apoptotic process. ${ }^{29,30}$ Second, RNA degradation may be used to ensure that all new transcripts of the dying cell are eliminated making the apoptotic process irreversible. ${ }^{11}$ Third, RNA turnover may have the general role of breaking down cellular components to facilitate recycling after apoptotic cells are phagocytosed. ${ }^{31}$ Additionally the studies by Mondino and Jenkins ${ }^{31}$ have shown that there is an accumulation of cytosolic RNAbinding proteins in apoptotic cells. Several of these binding proteins recognize $\mathrm{AU}$-rich sequences known to influence RNA stability. Furthermore, accumulation of these proteins occurs concomitantly with an increase in RNA turnover and apoptosis. These results suggest that degradation of RNA requires activation of a nuclease and also a possible role for accessory RNA-binding proteins. This multiple step process may provide a mechanism to target specific RNA molecules for degradation. Because 28S rRNA degradation does not appear to affect protein synthesis or any cellular process, it is possible that this molecule is not the primary target of the apoptotic RNase. Therefore, it will be important to establish whether other substrates exist and how they participate in the apoptotic process.

\section{Materials and Methods}

\section{Materials}

RPMI medium and TriZol reagent were purchased from Gibco-BRL (Gaithersburg, MD, USA) and fetal bovine serum from Irvine Scientific (Santa Ana, CA, USA). Dexamethasone was purchased from Steraloids (Wilton, NH, USA), anisomycin from Sigma Chemical Co. (St. Louis, MO, USA) and A23187 was purchased from Calbiochem (La Jolla, CA, USA). The general caspase inhibitor ZVAD was obtained from Kamiya (Seattle, WA, USA). All other reagents used were of the highest grade available from general suppliers.

\section{Cell culture}

The mouse thymoma cell lines, S49 Neo and S49 Bcl-2, are stable, clonal transformants of the parental S49.1 cell line. These cell lines were created by stably infecting S49.1 cells with recombinant amphotrophic retrovirus carrying the neomycin resistance gene alone or in combination with a bcl-2 complementary DNA as described previously. ${ }^{23}$ Both cell lines were maintained at $37^{\circ} \mathrm{C}, 7 \% \mathrm{CO}_{2}$ atmosphere in logarithmic growth $\left(10^{5}-10^{6}\right.$ cells $\left./ \mathrm{ml}\right)$ in RPMI supplemented with $10 \%$ heat-inactivated fetal bovine serum, $4 \mathrm{mM}$ glutamine, $100 \mathrm{U} / \mathrm{ml}$ penicillin, and $75 \mathrm{U} / \mathrm{ml}$ streptomycin. Agents used to induce death include dexamethasone (dex), anisomycin and A23187. ZVAD was used to inhibit caspase activity. Because different death signals have different kinetics for inducing apoptosis, treatments were selected so that, for most experiments, $30-40 \%$ of the cells were morphologically apoptotic as judged by light microscopy and trypan blue dye exclusion.

\section{Cell sorting}

S49 Neo cells were treated with $0.25 \mu \mathrm{M}$ dexamethasone for $42 \mathrm{~h}$ then stained with propidium iodide (PI) to eliminate cells that have lost their membrane integrity from further analysis. Simultaneous sorting of both the normal and shrunken viable populations of cells was accomplished using a Becton Dickinson FACSVantage equipped with CELLQuest software. Gates were set on a forward-scatter versus PI fluorescence dot plot. Cells were sorted into 5-ml tubes containing approximately $300 \mu \mathrm{l}$ of RPMI-1640 media and immediately processed for RNA isolation.

\section{Preparation and analysis of DNA and RNA}

For DNA isolation, $1 \times 10^{7}$ cells were pelleted, lysed in $5 \mathrm{mM}$ Tris- $\mathrm{HCl}$, $\mathrm{pH}$ 8.0, $20 \mathrm{mM}$ EDTA, 0.5\% Triton X-100 and 0.1\% SDS, and treated with $0.4 \mathrm{mg} / \mathrm{ml}$ proteinase $\mathrm{K}$ for $1 \mathrm{~h}$ at $55^{\circ} \mathrm{C}$. Lysates were extracted once with phenol-chloroform-isoamyl alcohol (25:24:1, by volume) and once with chloroform-isoamyl alcohol alone. One hundred $\mathrm{mM}$ $\mathrm{NaCl}$ was added and DNA precipitated by addition of two volumes of $100 \%$ ice cold ethanol at $-80^{\circ} \mathrm{C}$ for $2 \mathrm{~h}$. The suspension was centrifuged at $18000 \times g$ for $30 \mathrm{~min}$ at $4^{\circ} \mathrm{C}$. DNA pellets were air dried and resuspended in $10 \mathrm{mM}$ Tris- $\mathrm{HCl}, \mathrm{pH} 7.4,1 \mathrm{mM}$ EDTA, containing $0.3 \mathrm{mg} / \mathrm{ml}$ DNase-free RNase $A$ and incubated overnight at $37^{\circ} \mathrm{C}$. Fifteen $\mu \mathrm{g}$ DNA was loaded on $1.8 \%$ agarose gels that were subsequently stained with ethidium bromide. Total RNA was prepared from $2 \times 10^{7}$ cells using guanidine isothiocyanate and phenol. ${ }^{32}$ Two $\mu \mathrm{g}$ of total RNA was heated to $65^{\circ} \mathrm{C}$ and immediately loaded onto $1 \%$ non-denaturing gel that was subsequently stained with ethidium bromide.

\section{Northern blot analysis}

Total RNA was denatured using glyoxal and dimethyl sulfoxide and 2$3 \mu \mathrm{g}$ RNA was separated by electrophoresis through $1.8 \%$ agarose gels. RNA was transferred to nylon membranes as previously described. ${ }^{33}$ Filters were hybridized in a buffer containing $5 \times$ SSPE, $2 \times$ Denhardt's, $0.5 \%$ SDS, $100 \mu \mathrm{g} / \mathrm{ml}$ denatured and sheared salmon sperm DNA and $5^{\prime}$ end ${ }^{32}$ P-labeled oligonucleotide $\left(1 \times 10^{6}\right.$ c.p.m. $/ \mathrm{ml}$ hybridization fluid) complementary to positions $16-51$ ( $5^{\prime}$ probe) of the rat 28S rRNA.

\section{Acknowledgements}

This research was supported by the NIEHS Intramural Program. 


\section{References}

1. Arends MJ and Wyllie AH (1991) Apoptosis: mechanisms and roles in pathology. Int. Rev. Exp. Pathol. 32: 223-254

2. Schwartzman RA and Cidlowski JA (1993) Apoptosis: the biochemistry and molecular biology of programmed cell death. Endocrin. Rev. 14: 133-150

3. Cohen GM (1997) Caspases: the executioners of apoptosis. Biochem. J.326:1 16

4. Kumar S (1995) ICE-like proteases in apoptosis. TIBS 20: 198-202

5. Nicholson DW, Ali A, Thornberry NA, Vaillancourt JP, Ding CK, Gallant M, Gareau Y, Griffin PR, Labelle M, Lazebnik YA, Munday NA, Raju SM, Smulson ME, Yamin T-T, Yu VL and Miller DK (1995) Identification and inhibition of the ICE/CED-3 protease necessary for mammalian apoptosis. Nature 376: 37-43

6. Tewari M, Quan LT, O’Rourke K, Desnoyers S, Zeng A, Beidler DR, Poirier GG, Salvesen GS and Dixit VM (1995) Yama/CPP32b, a mammalian homolog of CED-3, is a crm-A-inhibitable protease that cleaves the death substrate poly (ADP-ribose) polymerase. Cell 81: 801-809

7. Villa P, Kaufmann SH and Earnshaw WC (1997) Caspases and caspase inhibitors. TIBS 22: 388-393

8. Bortner CD and Cidlowski JA (1999) Caspase independent/dependent regulation of $\mathrm{K}+$, cell shrinkage, and mitochondrial potential during lymphocyte apoptosis. J. Biol. Chem. 274: 21953-21962

9. Cidlowski JA, King KL, Evans-Storms RB, Montague JW, Bortner CD and Hughes FM (1997) The biochemistry and molecular biology of glucocorticoidinduced apoptosis in the immune system. Rec. Prog. Horm. Res. 52: 457-492

10. Compton MM and Cidlowski JA (1986) Rapid in vivo effects of glucocorticoids on the integrity of rat lymphocyte genomic deoxyribonucleic acid. Endocrinology 118: $38-45$

11. Cidlowski JA (1982) Glucocorticoids stimulate ribonucleic acid degradation in isolated rat thymic lymphocytes in vitro. Endocrinology 111: 184-190

12. MacDonald RG, Martin TP and Cidlowski JA (1980) Glucocorticoids stimulate protein degradation in lymphocytes: a possible mechanism of steroid-induced cell death. Endocrinology 107: 1512-1524

13. MacDonald RG and Cidlowski JA (1981) Glucocorticoids inhibit precursor incorporation into protein in splenic lymphocytes by stimulating protein degradation and expanding intracellular amino acid pools. Biochim. Biophys. Acta 678: 18-26

14. Wyllie AH (1980) Glucocorticoid-induced thymocyte apoptosis is associated with endogenous endonuclease activation. Nature 284: 555-556

15. Caron-Leslie L-AM, Evans RB and Cidlowski JA (1994) Bcl-2 inhibits glucocorticoid-induced apoptosis but only partially blocks calcium ionophore or cycloheximide-regulated apoptosis in S49 cells. FASEB J. 8: 639-645

16. Munck A and Leung K (1997) In: Receptors and Mechanisms of Action of Steroid Hormones, Part II, Marcell Dekker, New York, NY, pp. 311-397

17. Houge G, Doskeland SO, Boe R and Lanotte M (1993) Selective cleavage of $28 \mathrm{~S}$ rRNA variable regions $V 3$ and $V 13$ in myeloid leukemia cell apoptosis. FEBS Lett. 315: $16-20$

18. Houge G, Robaye B, Eikhom TS, Golstein J, Mellgren G, Gjertsen BT, Lanotte M and Doskeland SO (1995) Fine mapping of 28 S rRNA sites specifically cleaved in cells undergoing apoptosis. Mol. Cell. Biol. 15: 2051-2062
19. Delic J, Coppey-Moisan M and Magdelenat H (1993) X-Ray-induced transcription and apoptosis-associated loss of 28S rRNA in interphase human lymphocytes. Int. J. Radiat. Biol. 64: 39-46

20. Samali A, Gilje B, Doskeland SO, Cotter TG and Houge G (1997) The ability to cleave $28 \mathrm{~S}$ ribosomal RNA during apoptosis is a cell-type dependent trait unrelated to DNA fragmentation. Cell Death Differ. 4: 289-293

21. Harris AW (1970) Differentiated functions expressed by cultured mouse lymphoma cells: I. Specificity and kinetics of cell responses to corticosteroids. Exp. Cell Res. 60: 341-353

22. Ralph P, Hyman R, Epstein R, Nalcoinz I and Cohn M (1973) Independence of theta and TL surface antigens and killing by thymidine, cortisol, phytohemagglutinin, and cyclic AMP in a murine lymphoma. Biochem. Biophys. Res. Commun. 55: $1085-1091$

23. Miyashita Tand Reed JC (1992) bcl-2 gene transfer increases relative resistance of S49.1 and WEHI17.2 lymphoid cells to cell death and DNA fragmentation induced by glucocorticoids and multiple chemotherapeutic drugs. Cancer Res. 52: $5407-5411$

24. Bortner CD and Cidlowski JA (1996) Absence of volume regulatory mechanisms contributes to the rapid activation of apoptosis in thymocytes. Am. J. Physiol. 271: C950-C961

25. Borner CD, Hughes Jr FM and Cidlowski JA (1997) A primary role for K+ and $\mathrm{Na}+$ efflux in the activation of apoptosis. J. Biol. Chem. 272: 32436-32442

26. Hughes FM, Bortner CD, Purdy GD and Cidlowski JA (1997) Intracellular K+ suppresses the activation of apoptosis in lymphocytes. J. Biol. Chem. 272 : 30567-30576

27. Enari M, Sakahira H, Yokoyama H, Okawa K, Iwamatsu A and Nagata S (1998)A caspase-activated DNase that degrades DNA during apoptosis, and its inhibitor ICAD. Nature 391: 43-50

28. Sakahira H, Enari M and Nagata S (1998) Cleavage of CAD inhibitor in CAD activation and DNA degradation during apoptosis. Nature 391: 96-99

29. Chen M, Quintans J, Fuks Z, Thompson C, Kufe DW and Weichselbaum RR (1995) Suppression of Bcl-2 messenger RNA production may mediate apoptosis after ionizing radiation, tumor necrosis factor alpha, and ceramide. Cancer Res. 55: $991-994$

30. Tilly JT, Tilly KI, Kenton ML and Johnson AL (1995) Expression of members of the $\mathrm{Bcl}-2$ gene family in the immature rat ovary: equine chorionic gonadotropinmediated inhibition of granulosa cell apoptosis is associated with decreased Bax and constitutive Bcl-2 and Bcl-x long messenger ribonucleic acid levels. Endocrinology 136: 232-224

31. Mondino A and Jenkins MK (1995) Accumulation of sequence-specific RNAbinding proteins in the cytosol of activated T cells undergoing RNA degradation and apoptosis. J. Biol. Chem. 270: 26593-26601

32. Chomczynski P and SacchiN (1987) Single-step method of RNA isolation by acid guanidinium thiocyanate-phenol-chloroform extraction. Anal. Biochem. 162: $156-159$

33. Sambrook J, Fritsch EF and Maniatis T (1989) Molecular Cloning: A Laboratory Manual, 2nd edn., Cold Spring Harbor, NY, Cold Spring Harbor Laboratory 